Article

\title{
Expansion Analysis of Yangtze River Delta Urban Agglomeration Using DMSP/OLS Nighttime Light Imagery for 1993 to 2012
}

\author{
Huimin $\mathrm{Lu}^{1}$, Meiliang Zhang ${ }^{1, *}$, Weiwei Sun ${ }^{2, *}$ and Weiyue $\mathrm{Li}^{3}$ \\ 1 College of Science \& Technology, Ningbo University, Ningbo 315211, China; lucy1984@126.com \\ 2 Department of Geography and Spatial Information Techniques, Ningbo University, Ningbo 315211, China \\ 3 Institute of Urban Study, Shanghai Normal University, Shanghai 200234, China; lwy_326@126.com \\ * Correspondence: zhangmeiliang@nbu.edu.cn (M.Z.); sunweiwei@nbu.edu.cn (W.S.); \\ Tel.: +86-138-5788-9028 (M.Z.); +86-182-5879-6120 (W.S.)
}

Received: 24 December 2017; Accepted: 1 February 2018; Published: 5 February 2018

\begin{abstract}
Investigating the characteristics of urban expansion is helpful in managing the relationship between urbanization and the ecological and environmental issues related to sustainable development. The Defense Meteorological Satellite Program/Operational Line-scan System (DMSP/OLS) collects visible and near-infrared light from the Earth's surface at night without moonlight. It generates effective time series data for mapping the dynamics of urban expansion. As a major urban agglomeration in the world, the Yangtze River Delta Urban Agglomeration (YRDUA) is an important intersection zone of both the "Belt and Road Initiative" and the "Yangtze River Economic Belt" in China. Therefore, this paper analyses urban expansion characteristics of the YRDUA for 1993-2012 from urban extents extracted from the DMSP/OLS for 1993, 1997, 2002, 2007, and 2012. First, calibration procedures are applied to DMSP/OLS data, including intercalibration, intra-annual composition, and inter-annual series correction procedures. Spatial extents are then extracted from the corrected DMSP/OLS data, and a threshold is determined via the spatial comparison method. Finally, three models are used to explore urban expansion characteristics of the YRDUA from expansion rates, expansion spatial patterns, and expansion evaluations. The results show that the urban expansion of the YRDUA occurred at an increasing rate from 1993-2007 and then declined after 2007 with the onset of the global financial crisis. The Suxichang and Ningbo metropolitan circles were seriously affected by the financial crisis, while the Hefei metropolitan circle was not. The urban expansion of the YRDUA moved from the northeast to the southwest over the 20-year period. Urban expansion involved internal infilling over the first 15 years and then evolved into external sprawl and suburbanization after 2007.
\end{abstract}

Keywords: urban expansion; DMSP/OLS; Yangtze River Delta Urban Agglomeration; metropolitan circle; remote sensing

\section{Introduction}

Urban expansion is a phenomenon of urbanization that is closely correlated with demographic dynamics and socioeconomic development [1-4]. Over the last three decades, China has undergone unprecedented and rapid urban expansion [5,6]. In particular, the Yangtze River Delta Urban Agglomeration (YRDUA), one of six typical mega-city regions found across the world, has reached the highest density and urbanization levels in China. Such rapid urbanization has spurred natural resource depletion and a series of ecological and environmental problems $[7,8]$, e.g., quality deterioration, pollution of urban surface water, exacerbated urban heat island effects, and the degradation of ecosystem functioning $[9,10]$. Therefore, a timely and general analysis of urban expansion (e.g., expansion rates, expansion patterns, and expansion evaluations) is crucial to understanding the characteristics of 
urbanization processes and for estimating environmental consequences to address such urbanization problems in China.

Currently, three main data resources are available for investigating urban expansion problems, i.e., socioeconomic data on population and economy, location-based social network data, and remote sensing imagery $[11,12]$. Socioeconomic data directly reflect urban expansion patterns with respect to population and economic changes. Unfortunately, such data lack adequate spatial information and are usually aggregated within coarse administrative divisions. Location-based social network data reflect human activities and can be used to delineate urban boundaries. Unfortunately, such data only cover limited time periods due to their short history, and they thus cannot be used to monitor long-term urban expansion processes. Remote sensing, owing to its unique advantages regarding rapid and periodic data collection and spatial coverage, has served as a powerful technique to characterize and quantify urban extents and dynamic changes [13-15]. Widely used medium-to-high-remote sensing images, e.g., Landsat TM/ETM+, IKONOS and Quickbird, provide finer land cover information at city and smaller scales. Unfortunately, these remote sensing data sources are impractical to use at larger scales such as the YRDUA region. The above images are negatively affected by the presence of clouds and poor atmospheric conditions, especially in humid subtropical and tropical regions [16]. In addition, the limited spatial coverage of such data results in the generation of numerous images, necessitating considerable levels of image processing and thus involving the application of considerable time and financial resources to obtain an urban map of the YRDUA region $[7,9,17]$.

Satellite remote sensing images generated from coarse spatial resolution sensors ( $>500 \mathrm{~m}$ ) have accordingly served as major data sources for large-scale urban mapping. However, Moderate Resolution Imaging Spectroradiometer (MODIS) remote sensing imagery have coarse spatial resolutions, and the dataset only became available after 2000. The short-term nature of the dataset, along with its low level of data integrity due to the presence of clouds, impedes the generation of large-scale urban expansion maps of the YRDUA. Instead, the Defense Meteorological Satellite Program/Operational Line-scan System (DMSP/OLS) collects nighttime light (NTL) data at a daily temporal resolution, and such data provide spatially explicit observations of human settlements at night without moonlight [18-21]. The archived annual NTL data cover a relatively long time span (i.e., 1992-2013) and are freely accessible. A number of efforts have been made to use overall measures of NTL data to estimate demographic and socioeconomic activities at large scales, e.g., for mapping imperious surface areas [22,23], predicting GDP growth [24,25], estimating electricity consumption [26,27], evaluating light pollution [28], and measuring population density and agglomeration $[29,30]$.

In particular, NTL data have been regarded as cost-effective tools for mapping urban areas [30-32] and urban expansion dynamics [12,33,34]. Various researchers have investigated urban expansion at the global, national, and regional scales. At the global scale, Zhang and Seto developed an iterative unsupervised classification based on NTL data for 1992 to 2008 and compared urban dynamic patterns for India, China, Japan, and the United States [35]. Using normalized difference vegetation index data drawn from MODIS and NTL imagery for 1992-2012, Liu investigated spatiotemporal relations between urbanization and vegetation degradation for 50 large metropolises [36]. Cai combined MODIS data and NTL datasets for 2001-2012 to explore correlations between urbanization and thermal environments in China and the United States [37]. Xie and Weng made global inter-calibration vegetation-based spatial adjustments to NTL data and used the obtained dataset to update and backdate large-scale urban changes occurring in the United States and China from 1993 to 2012 [38]. At the national level, Liu and He corrected multi-year multi-satellite NTL data and extracted dynamics of urban expansion for China for 1992 to 2008 [12]. Gao used NTL data to analyze dynamics of urbanization levels in China for 1992 to 2012 [39]. Using same-period NTL data, Tan explored urbanization and rural transition patterns occurring in Mainland China [40]. Ma partitioned NTL data into five night-time lighting areas for individual cities and investigated the growth characteristics of 271 cities in China for 1992 to 2012 [2]. Ju used NTL data for 1992 to 2013 to identify various urban dynamics found in Mainland China [11]. At the regional scale, Yi constructed an urban light index from NTL data 
for 1992 to 2010 and quantitatively evaluated the urbanization processes and expansion rates of 34 prefecture-level cities in northeastern China [41]. Li derived a time series vegetation adjusted NTL urban index (VANUI) from DMSP/OLS data and analyzed urban dynamics of the southeastern United States for 1992 to 2013 [42]. Gao [43] and Huang [44] used NTL data for 1992 to 2015 and compared common characteristics and distinctive features of city-size distributions of three urban agglomerations (Beijing-Tianjin-Hebei, the Yangtze River Delta, and the Pearl River Delta) via Pareto regression and rank clock methods. Zou detected urban changes from DMSP/OLS data for 1992 to 2011 and evaluated urban expansion intensity and landscape metrics of the middle reaches of the Yangtze River (MRYR) in China [45]. Zhou extracted the urban built-up area of the MRYR in China from DMSP/OLS, Landsat, and MODIS data and explored spatial distribution and evolution characteristics of three metropolitan circles (i.e., Chang-Zhu-Tan, Wuhan, and Poyang Lake) [46]. The above studies have furthered the application of the DMSP/OLS to the study of urban expansion in the YRDUA.

The YRDUA is one of the largest economic core regions in China, and it serves as an important intersection zone of the "Yangtze River Economic Belt" and the "Belt and Road Initiative". The Belt and Road Initiative proposed in 2013 is China's development strategy for forging connectivity and cooperation between Eurasian countries. The YRDUA has undergone rapid urbanization and dramatic economic growth since the reform and open policy of 1978 was put into force. In 2013, the YRDUA's urbanization rate reached 67.9\%, 1.3 times the national average. In 2014, the Gross Domestic Product (GDP) of the YRDUA reached 12.67 trillion RMB, accounting for $18.5 \%$ of China's total GDP. Its population has reached over 150 million, accounting for $11 \%$ of China's population. In 2016, the Chinese government approved of the "Yangtze River Delta Urban Agglomeration Development Plan (YRDUADP)" and aimed to construct a network spatial pattern including one core megacity, five metropolitan circles, and four development belts. Unfortunately, few researchers have carefully analyzed urban expansion characteristics of the YRDUA using the DMSP/OLS for 1992 to 2012, particularly at the metropolitan circle level. Recently, Wang [47] extracted the physical boundaries of urban clusters of the Yangtze River Delta Area (YRDA) from NTL images and analyzed cluster structures of the YRDA at two levels, i.e., the entire YRDA and its metropolitan area. Unfortunately, the study adopted a dated definition of the YRDA and did not apply new spatial boundaries of the YRDUA defined in the 2016 YRDUADP. Moreover, the paper is limited in its cluster structure analysis of the four metropolitan areas and does not explore urban expansion characteristics of metropolitan circles in the YRDUA.

Therefore, based on the new YRDUADP for 2016, the primary objective of this paper is to investigate urban expansion characteristics of the YRDUA from DMSP/OLS NTL data at agglomeration and metropolitan circle levels. To the best of our knowledge, our work is the first to investigate urban expansion characteristics of the five metropolitan circles of the YRDUA, and it will contribute to the development of sustainable urban planning decisions and to the forecasting potential future changes in YRDUA growth patterns. The present agglomeration-level analysis reveals overall dynamics of urban expansion in the YRDUA. The metropolitan circle-level analysis presented here compares the spatial expansion patterns of five different metropolitan circles. First, DMSP/OLS data were calibrated to render DN values for different years and drawn from different satellites continuous and comparable. Dynamics of urban extents of the YRDUA were then extracted from DMSP/OLS data for 1993-2012. The definition of "urban extents" should be related to Chinese official census data. Therefore, the "urban extent" is defined in this paper as places dominated by artificial surfaces in an urban area (i.e., the municipal district) of one city, and it does not include artificial surfaces of county or suburban areas. Three models on expansion rates, spatial expansion patterns, and expansion evaluations were then adopted to comprehensively quantify urban expansion characteristics. Finally, spatiotemporal expansion characteristics of the YRDUA were analyzed at two main levels, i.e., the agglomeration and metropolitan circle levels, and the urban expansion status of the YRDUA was evaluated. 


\section{Datasets}

\subsection{Study Area}

The YRDUA is located along the east coast of China and is the most densely populated area in China. The spatial extent of the YRDUA covers the megacity of Shanghai and three neighboring provinces (Jiangsu, Zhejiang, and Anhui), as shown in Figure 1. The YRDUA covers an area of $211,700 \mathrm{~km}^{2}$, accounting for $2.2 \%$ of China's total land area. Following from the YRDUA development plan developed by the Chinese government in 2016, the YRDUA mainly includes one core megacity (Shanghai) and five metropolitan circles: the Nanjing, Hangzhou, Ningbo, Suxichang, and Hefei metropolitan circles. The Nanjing metropolitan circle is centered at the city of Nanjing and includes three cities: Nanjing, Zhenjiang, and Yangzhou. This Hangzhou metropolitan circle is centered at the city of Hangzhou and includes four cities: Hangzhou, Jiaxing, Huzhou, and Shaoxing. The Ningbo metropolitan circle is centered at the city of Ningbo and includes three cities: Ningbo, Zhoushan, and Taizhou. The Suxichang metropolitan circle is centered at the city of Suzhou and includes three cities: Suzhou, Wuxi, and Changzhou. The Hefei metropolitan circle is centered at the city of Hefei and includes three cities: Hefei, Wuhu, and Maanshan.

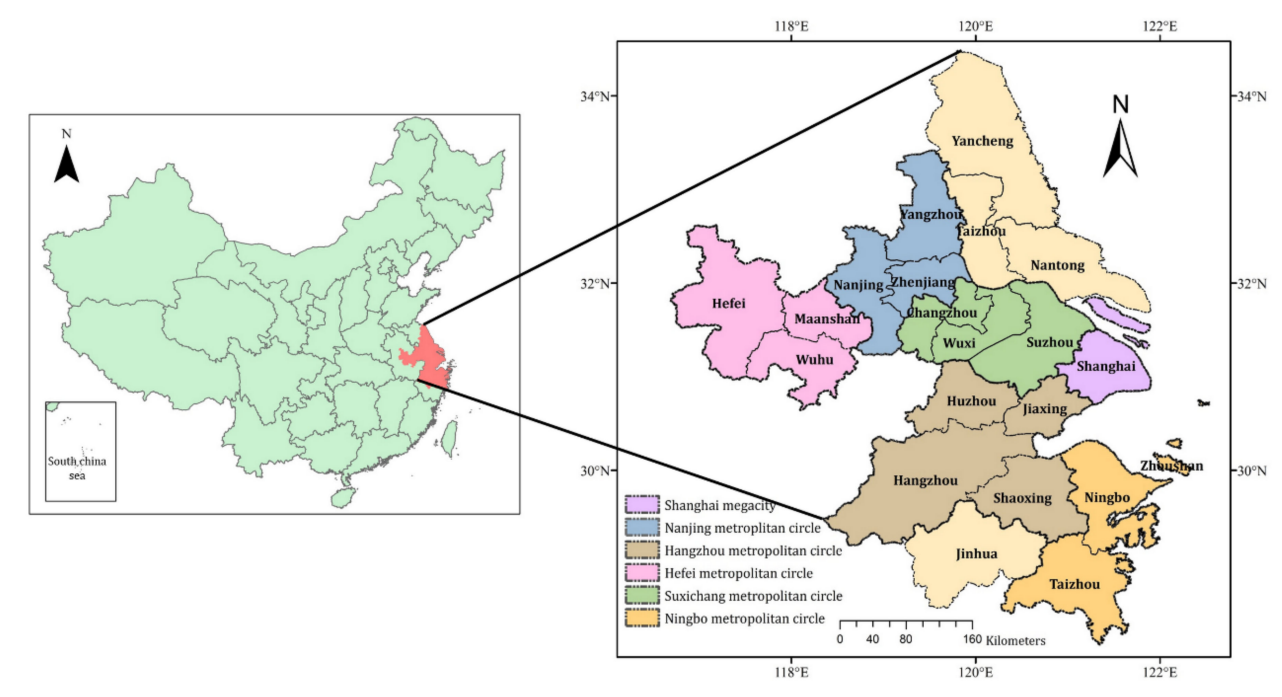

Figure 1. Yangtze River Delta Urban Agglomeration (YRDUA) study area.

\subsection{Data Acquisition and Pre-Processing}

Four types of data were used in this study: DMSP/OLS NTL data, urban built-up census data (for municipal districts), non-agricultural population statistical data, and administrative boundary data. Table 1 presents the formats and sources of our main data sources. The V4DNLTS dataset of DMSP/OLS stable light data was obtained from the NGDC website (available at https:/ /ngdc.noaa.gov/eog/dmsp/ downloadV4composites.html). This dataset is a cloud-free composite assembled from all archived smooth resolution data of the DMSP/OLS. The stable light data cover light generated from cities, towns, and other sites with resistant lighting with ephemeral events (e.g., fires, gas flares, volcano eruptions, and background noise) removed [25,48]. The data are generated at a spatial resolution of 30 arc seconds spanning $-180^{\circ}$ to $180^{\circ}$ in longitude and $-65^{\circ}$ to $75^{\circ}$ in latitude. The value of a DMSP/OLS stable NTL data point represents the mean light intensity levels observed within each year ranging from values of 1 to 63. We obtained global DMSP/OLS data for 1993, 1997, 2002, 2007, and 2012, and then extracted experimental NTL data from the YRDUA administrative boundary. Averaged values of two annual composite images for 1997, 2002, and 2007 were used to minimize discrepancies between composites drawn from different satellites. The DMSP/OLS datasets were projected via Lambert Azimuthal Equal Area projection and were resampled at a spatial resolution of $1 \mathrm{~km}$. 
Table 1. The datasets used in our study.

\begin{tabular}{cccc}
\hline Data Type & Year & Format & Data Source \\
\hline DMSP/OLS NTL data & $1993,1997,2002,2007,2012$ & GeoTiff & http://ngdc.noaa.gov/eog/dmsp/downloadV4composites.html \\
\hline Built-up area census data & $1993,1997,2002,2007,2012$ & Excel & http://data.cnki.net/yearbook/ \\
\hline $\begin{array}{c}\text { Urban non-agricultural } \\
\text { population data }\end{array}$ & $1993,1997,2002,2007,2012$ & Excel & http://data.cnki.net/yearbook/ \\
\hline $\begin{array}{c}\text { Administrative } \\
\text { boundary data }\end{array}$ & $1993,1997,2002,2007,2012$ & Shp & http://www.ngcc.cn \\
\hline
\end{tabular}

Urban built-up census data (for municipal districts) were obtained from the China City statistical yearbook (available at http:/ / data.cnki.net/yearbook/). Urban non-agricultural population statistical data were drawn from the China population statistical yearbook (available at http:/ / data.cnki.net/ yearbook/). Administrative boundary data were collected from the National Geomatics Center of China (available at http:/ / www.ngcc.cn).

\section{Methodology}

Our methodology involved three main steps: (1) DMSP/OLS data calibration; (2) urban extent extraction; and (3) urban expansion characteristic analysis. Figure 2 shows a flowchart of our urban expansion analysis in the YRDUA. First, three processing tasks were carried out in the data calibration phase, i.e., intercalibration, intra-annual composition, and inter-annual series correction. Then, using the corrected DMSP/OLS time series data, the threshold of the NTL data was estimated via spatial comparisons. The urban built-up extent of the YRDUA was extracted by applying binary segmentation to the corrected NTL data. Finally, urban expansion characteristics were analyzed from expansion rates, expansion spatial patterns, and expansion evaluation models.

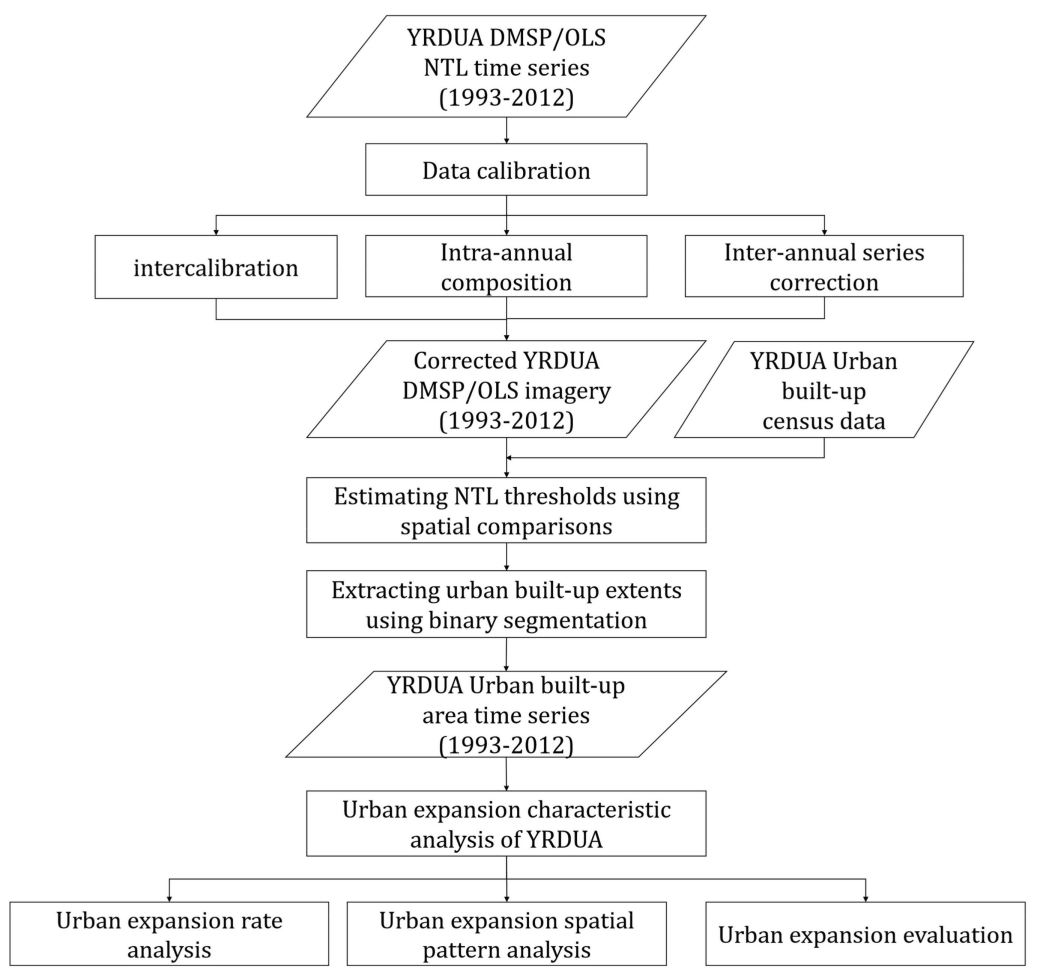

Figure 2. Flowchart of the urban expansion characteristic analysis of the YRDUA. 


\subsection{Defense Meteorological Satellite Program/Operational Line-scan System (DMSP/OLS) Data Calibration}

The DMSP/OLS stable NTL data were collected from various satellite sensors and had not been calibrated against radiation. Due to the use of different sensors, varying transit times between satellites, and sensor deterioration, data collected by sensors aboard different satellites vary considerably $[39,49]$. For instance, two different satellites will generate different digital number (DN) values for the same year; a single satellite can exhibit abnormal fluctuations in DN values for different years; the number of lit pixels derived differs considerably between satellites for the same year; and the number of lit pixels derived from the same satellite can decrease abnormally in different years [12]. It is thus necessary to calibrate DMSP/OLS data to improve their continuity and comparability and to render urban extent results for different years and drawn from different satellites comparable.

Our DMSP/OLS data calibration procedure involved three steps, i.e., intercalibration, intra-annual composition, and inter-annual series correction [12].

\subsubsection{Intercalibration}

Intercalibration involved improving the comparability of DMSP/OLS data for the YRDUA for 1993 to 2012 [42]. We employed Elvidge et al.'s [20] method. Based on an analysis of GDP and built-up area census data for major cities in China for 1993-2012, NTL data drawn from the F16 satellite for 2006 were used as a reference dataset, as they present the highest cumulative DN value. A second-order regression model was developed for each satellite and from empirically derived coefficients by comparing DN values of other images to 2016 reference data drawn from the F16 satellite. All the NTL data were inter-calibrated using the above regression model.

\subsubsection{Intra-Annual Composition}

The intra-annual composition makes full use of information derived from two satellites for the same year while removing intra-annual unstable lit pixels. Following the method developed by Liu et al. [12], the intra-annual composition for DMSP/OLS NTL data was determined from averaged DN values for two DMSP/OLS images. A lit pixel was defined as an intra-annual unstable lit pixel when it was detected by only one satellite.

\subsubsection{Inter-Annual Series Correction}

Inter-annual series correction involves limiting inter-annual discrepancies between DN values to minimum levels. We executed inter-annual series correction using the method proposed by Liu et al. [12]. A lit pixel was considered to be an inter-annual unstable lit pixel when it was present in an earlier image, but was not found in a later DMSP/OLS NTL image. DN values of inter-annual unstable lit pixels were replaced with a value of zero. The $\mathrm{DN}$ value of each inter-annual stable lit pixel was corrected to ensure that its DN value for an early image did not exceed that of an image collected later on.

After the three procedures were applied, the intra-annual unstable lit pixels were removed, and inter-annual discrepancies between $\mathrm{DN}$ values were limited to minimal values. $\mathrm{DN}$ values of the DMSP/OLS NTL data for different years $(1993,1997,2002,2007$, and 2012) and drawn from different satellites were in turn rendered continuous and comparable.

\subsection{Urban Extent Extraction from Corrected DMSP/OLS Nighttime Light (NTL) Data}

Thresholding techniques are typically used to separate urban extent information from DMSP/OLS NTL data. Currently, some methods are used to estimate the thresholds of urban extents such as empirical thresholding [50], the mutation detection method [51], and spatial comparisons based on auxiliary data [52]. In this study, using urban built-up census data, we applied the spatial comparison method to determine the threshold of the NTL data. Built-up area census data for 1993, 1997, 2002, 2007, and 2012 published by the China National Bureau of Statistics reflects actual conditions of urban 
built-up areas in the YRDUA. Therefore, the threshold of DMSP/OLS NTL data can be determined by comparing the total extent of urban built-up areas to corresponding census data. On the other hand, it is difficult to identify a single threshold for all urban built-up areas of the YRDUA due to regional variations in physical environments and social-economic development levels. We thus estimated the NTL threshold for 21 major cities and then separately extracted urban extents from corresponding DMSP NTL data time series.

For each city, we used the following approach to determine NTL data thresholds via spatial comparisons. First, an empirical threshold (e.g., 50) was applied, and the light area of the DMSP/OLS data was obtained after thresholding. The total light patch area was then compared to corresponding urban built-up area census data to quantify differences. By manually tuning the threshold parameter, when the total area of the urban extent extracted from NTL data best matched built-up area census data for the same city, the optimal NTL data threshold was identified. Finally, extracted light patches with the optimal threshold were regarded as urban extents from the DMSP/OLS NTL data. It should be noted that the DMSP/OLS light patches of the core megacity of Shanghai and of five central cities (Nanjing, Hangzhou, Ningbo, Hefei, and Suzhou) were extracted separately from municipal and non-municipal districts. This was applied due to the internally heterogeneous nature of the physical environment and social-economic development in these six key cities and to benefit our expansion analysis. The threshold to the applied NTL data for municipal districts of the six key cities was set to twice that of the non-municipal districts. Using the above optimal thresholds, urban extents of the YRDUA were extracted from the corrected DMSP/OLS NTL data for 1993, 1997, 2002, 2007, and 2012, and dynamics of urban expansion in the YRDUA were in turn identified.

\subsection{Urban Expansion Characteristic Analysis}

In this study, we analyzed characteristics of urban expansion in the YRDUA based on three main variables, namely, expansion rates, expansion patterns, and expansion evaluations.

\subsubsection{Urban Expansion Rate Model}

The urban expansion speed denotes the annual growth rate of the urban built-up area at different stages of the study period. It represents overall trends of urban expansion occurring at different stages. In this study, we used the annual growth area $(A G A)$ of the urban built-up area to quantify the expansion rate of the urban areas. The $A G A$ is defined as the following equation:

$$
A G A=\frac{U A_{i+t}-U A_{i}}{t}
$$

where $U A_{i}$ and $U A_{i+n}$ are the urban built-up areas of the $i$-th and $i+t$-th years, respectively, and where $t$ is the time interval of the calculation period (in years).

\subsubsection{Urban Expansion Spatial Pattern Model}

We used the standard deviational ellipse (SDE) and buffer compactness index (BCI) to measure spatial patterns of urban expansion. The SDE was first proposed by Lefever to identify characteristics of geospatial distribution [53]. It is now widely used as a centrographic measure to depict spatial characteristics of a set of point locations. The SDE is based on the average center of a set of discrete point locations and on the standard distance of other point locations to the average center in the $x$ and $y$ directions. The two measures define the axes of an ellipse covering the distribution of features. The SDE identifies the overall location of a set of points based on the center of the ellipse and describes the spread and extent of point locations along the two orthogonal axes of minimum and maximum spreads. Moreover, the rotation angle reflects main trend directions, thus allowing one to determine whether the distribution of features is elongated and thus has a particular orientation. The orientation is the rotation of the long axis measured clockwise from north. In this study, to better demonstrate expansion characteristics of urban built-up areas, the SDE was weighted by the average light density 
$I_{j}$ to calculate the weighted SDE and to better demonstrate spatial characteristics of urban expansion of the YRDUA. $I_{j}$ is defined as follows [54]:

$$
I_{j}=\sum_{i=1}^{D N_{\max }} D N_{i} \times \frac{n_{i}}{N \times D N_{\max }}
$$

where $I_{j}$ is the average light intensity of city $j$; where $D N_{i}$ and $n_{i}$ are the $i$-th level $D N$ values and their counts, respectively; where $N$ is the total number of pixels; and where $D N_{\max }$ is the maximum $D N$ value.

The $\mathrm{BCI}$ is an important index of urban compactness based on spatial external contours and delineates the density gradient of urban settlement from a city center. It not only measures an individual built-up area patch, but also describes the fragmentation of an urban landscape [55]. The BCI is calculated as follows:

$$
\mathrm{BCI}=\frac{2 \sqrt{\pi \mathrm{A}}}{P}
$$

where $\mathrm{A}$ is the area of the urban built-up patch and where $P$ is the perimeter of the built-up area. The BCI ranges from 0 to 1 , and a higher BCI value denotes a more compact urban built-up area. A BCI of close to 1 denotes an urban shape of closer to a circle, whereas a $\mathrm{BCI}$ of close to 0 denotes a long and narrow urban area. Generally, when urban outer contours are more compact, urban expansion occurs through internal infilling. In contrast, when an urban built-up area is more widely distributed, urban expansion occurs along the edges of an urban area [56].

\subsubsection{Urban Expansion Evaluation Model}

Urban non-agricultural population growth is significantly correlated with urban expansion. Therefore, we adopted the elastic coefficient of urban expansion-population growth to reflect coordination between urban expansion and non-agricultural population growth and to evaluate the state of urban expansion. The elastic coefficient of urban expansion-population growth $R_{(i)}$ is defined as follows:

$$
R_{(i)}=\left(\frac{U A_{i+t}-U A_{i}}{U A_{i}}\right)\left(\frac{P O P_{i+t}-P O P_{i}}{P O P_{i}}\right)
$$

where $U A_{i+t}, U A_{i}, P O P_{i+t}$, and $P O P_{i}$ denote the urban built-up area and the urban non-agricultural population at times $i+t$ and $i$, respectively, and where $t$ is the time interval of the calculation period (in years). Researchers from the China Academy of Urban Planning and Design investigated long-term urbanization processes occurring in China's main cities and found that levels of urban expansion remain relatively moderate when $R_{(i)}$. is equal to 1.12. An $R_{(i)}$ value of more than 1.12 denotes that urban expansion is occurring too quickly. In contrast, an $R_{(i)}$ value of less than 1.12 denotes an excessively gradual urban expansion rate that does not support urban population growth.

\section{Results}

\subsection{Urban Expansion Rate Analysis}

Figure 3 illustrates spatial changes in the urban built-up area of the YRDUA for 1993-2012. Urban built-up areas of the YRDUA change greatly throughout the 20-year period. Figure 4 plots the AGAs of urban built-up areas for the entire YRDUA and for its five metropolitan circles. From the figure, the urban built-up area of the YRDUA undergoes accelerated expansion from 1993 to 2007. However, after 2007, the urban expansion rate begins to decline slightly. Expansion rate plots of the five metropolitan circles show similar patterns. From 1993 to 2007, four metropolitan circles (the Hangzhou, Ningbo, Suxichang, and Hefei metropolitan circles) show increasing expansion rates. Expansion rates of most of the metropolitan circles decline after 2007, except for those of the Hefei metropolitan circle. In particular, the Ningbo and Suxichang metropolitan circles undergo more significant levels of urban built-up area expansion rate decline than the other circles after 2007. The Hefei metropolitan circle 
consistently undergoes expansion over the 20-year period, with its expansion rates being highest from 2007.

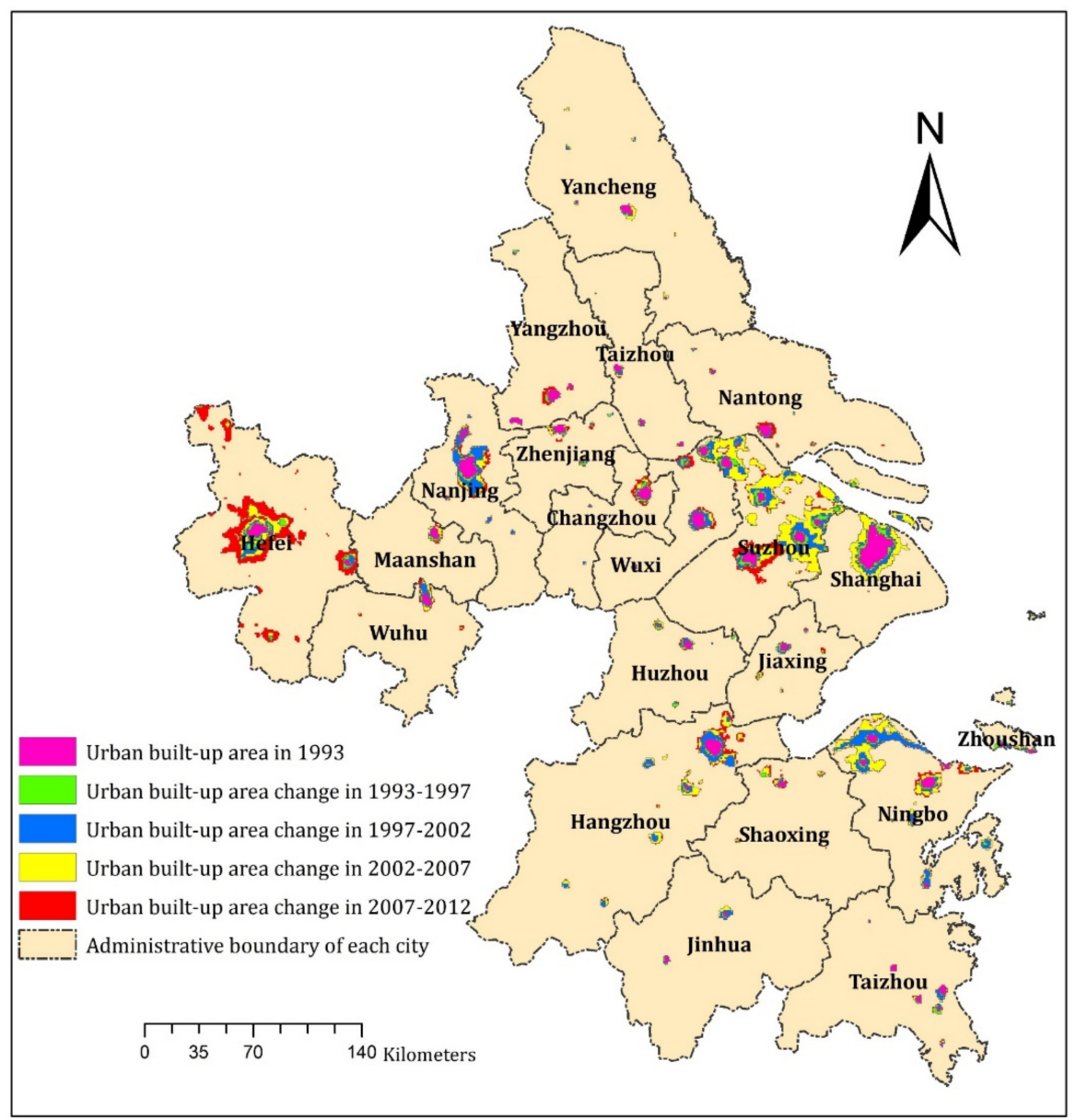

Figure 3. Changes in the urban built-up area of the YRDUA for 1993-2012 extracted from corrected DMSP/OLS NTL data.

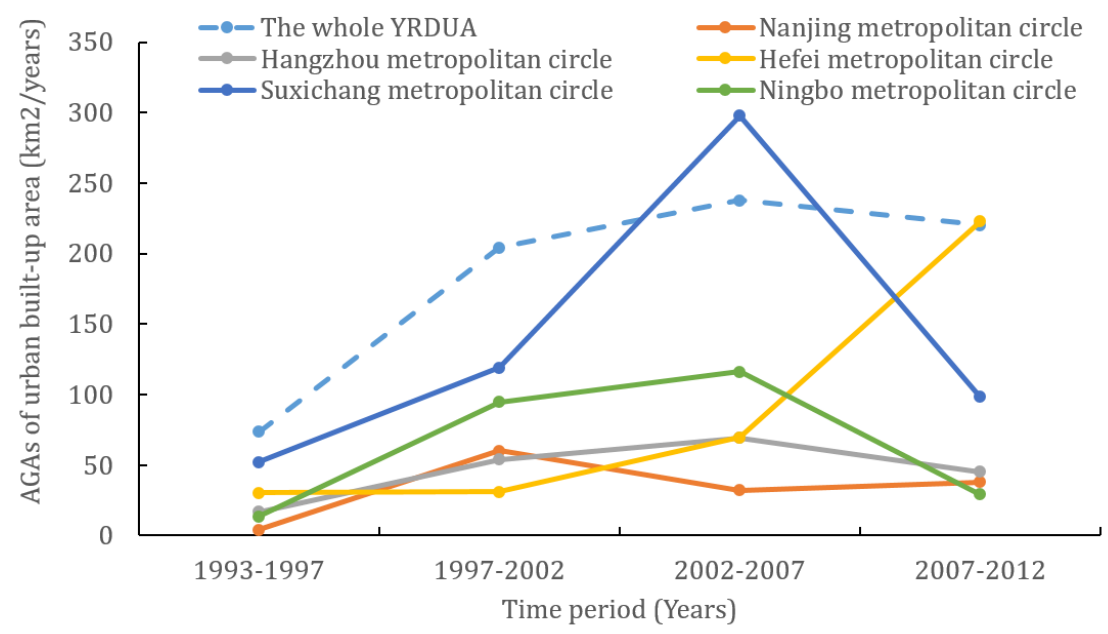

Figure 4. Annual growth area (AGA) plots of the YRDUA urban built-up area for 1993-2012. 


\subsection{Urban Expansion Spatial Pattern Analysis}

Figures 5 and 6 show the map of SDEs for the YRDUA and for five metropolitan circles for 1993-2012. The center positions, major axis, and minor axis of these ellipses diverge greatly across the 20-year period. Figure 7 plots changes in the locations of SDE centers occurring from 1993 to 2012 for the YRDUA and for the five metropolitan circles. Figure 7a shows that SDE center changes in the YRDUA over the 20-year period can be characterized as follows: westward shifts in the latitude direction and southward shifts in the longitude direction. In the latitude direction, the most significant westward shift in the SDE center occurs from 1993 to 1997, covering an offset distance of roughly $32 \mathrm{~km}$. After 1997, SDE centers undergo minor fluctuations in the east-west direction of less than $2.5 \mathrm{~km}$. In the longitude direction, SDE centers of the YRDUA shift north by approximately $12 \mathrm{~km}$ from 1993 to 1997 and then move south after 1997. The more significant southward shift in SDE centers occurs from 2007-2012, covering an offset distance of approximately $19 \mathrm{~km}$.

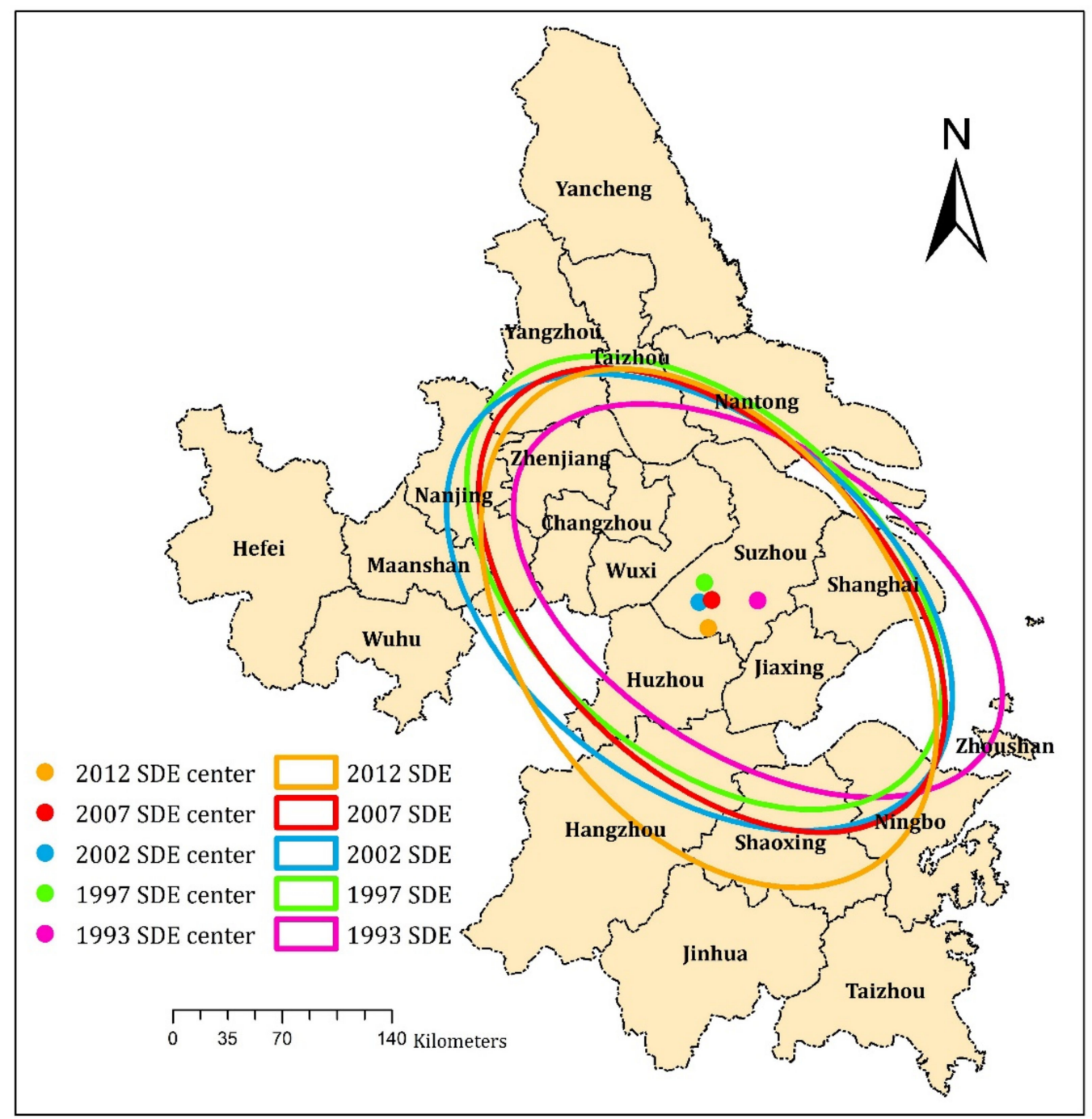

Figure 5. Map of standard deviational ellipses (SDEs) for 1993 to 2012 for the YRDUA.

Figure $7 \mathrm{~b}$ shows that SDE centers of the Nanjing metropolitan circle shifted north in the latitude direction and east in the longitude direction over the 20-year period. Figure 7c shows that SDE centers of the Hangzhou metropolitan circle moved south in the latitude direction during 1993-2012. In the longitude direction, SDE centers first shifted slightly eastward from 1993 to 2007 and then shifted 
significantly to the west of the circle. SDE centers of the Hefei metropolitan circle shifted south in the latitude direction over the 20-year period while its shift in longitude was less significant and tended west. SDE centers of the Suxichang metropolitan circle shown in Figure 7e moved south in the latitude direction and east in the longitude direction. Figure $7 \mathrm{f}$ shows that SDE centers of the Ningbo metropolitan circle underwent the most significant southward shift in the latitude direction from 1993-1997 and then shifted north after 1997. In the longitude direction, its SDE centers first shifted considerably to the west from 1993-1997 and then shifted slightly eastward from 1997 to 2012. From the above observations the YRDUA and the five metropolitan circles underwent clear southwestern shifts in SDE centers over the 20-year period.

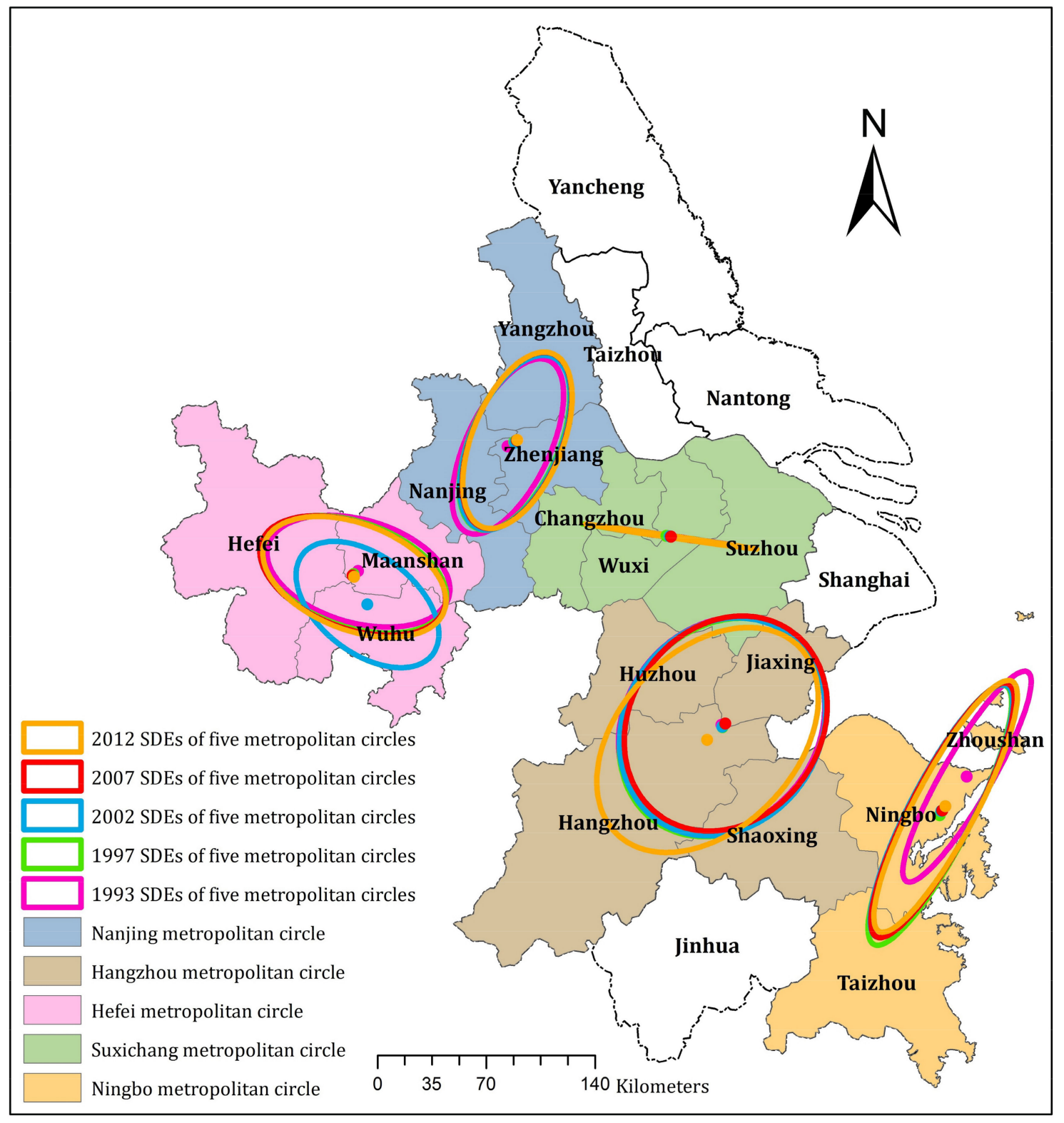

Figure 6. Map of SDEs for 1993 to 2012 for five metropolitan circles. 


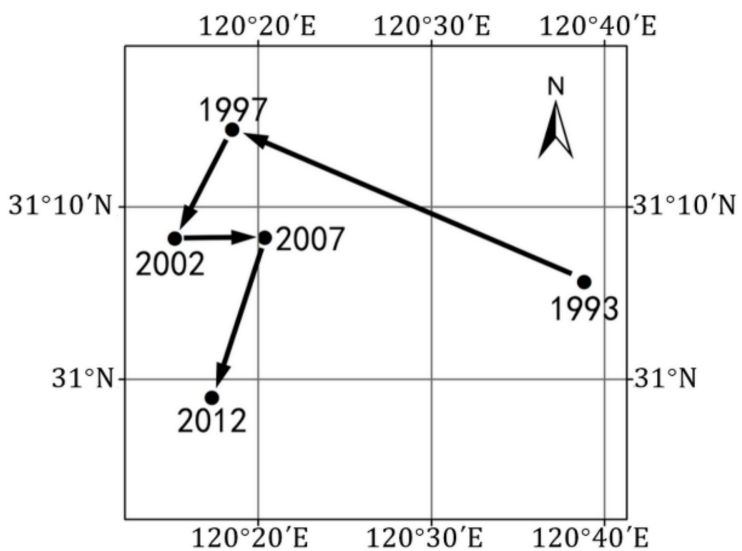

(a)

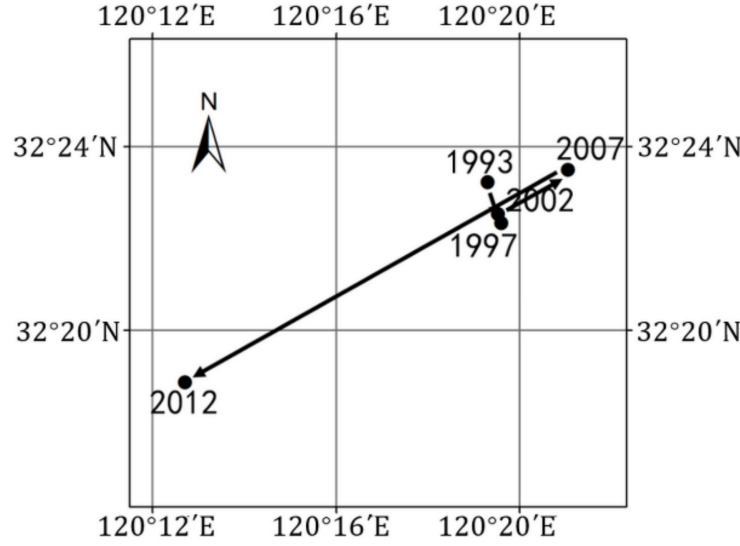

(c)

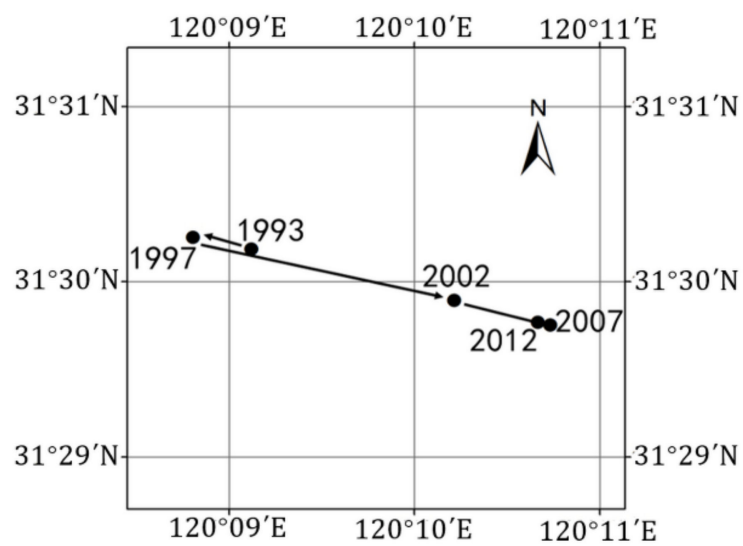

(e)

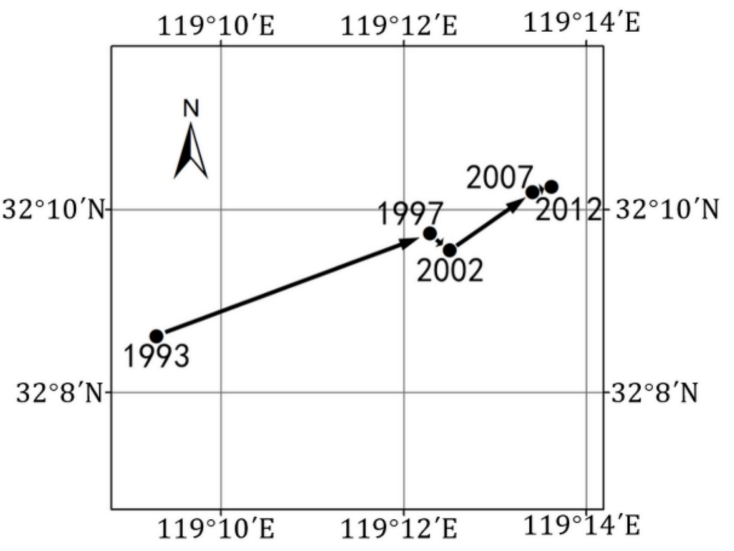

(b)

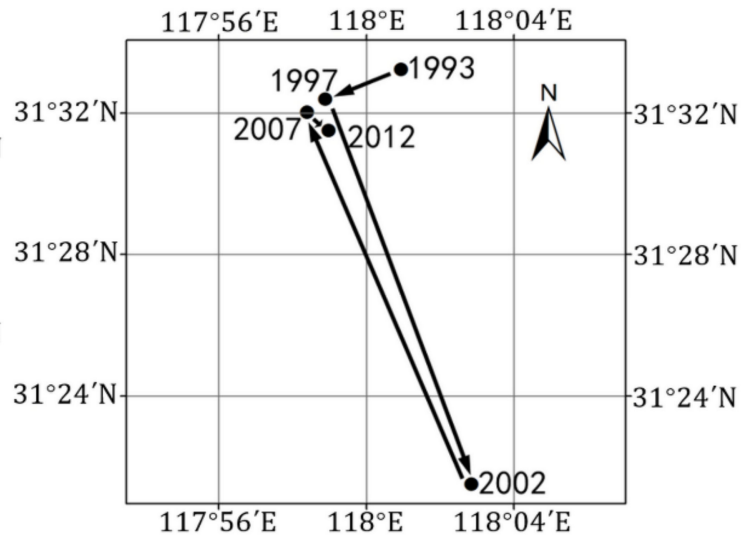

(d)

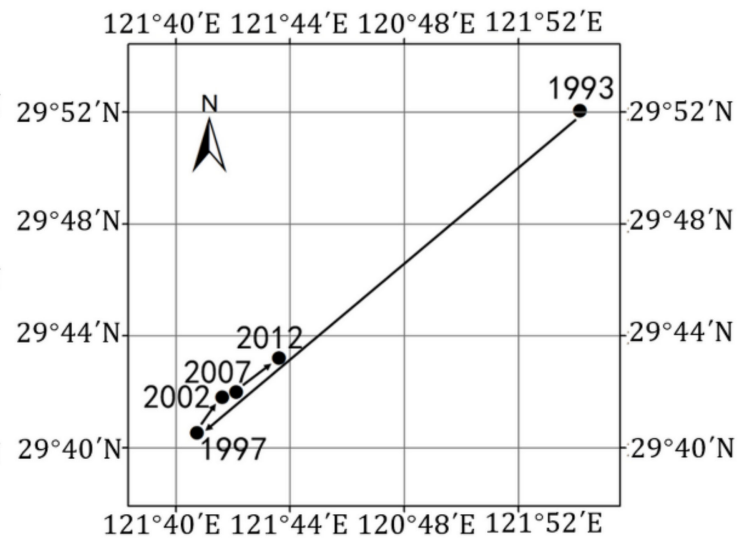

(f)

Figure 7. SDE center location changes occurring from 1993 to 2012 for (a) The YRDUA; (b) Nanjing metropolitan circle; (c) Hangzhou metropolitan circle; (d) Hefei metropolitan circle; (e) Suxichang metropolitan circle; and (f) Ningbo metropolitan circle.

Table 2 compares BCIs of the core megacity of Shanghai to those of the five metropolitan circles for 1993-2012. The megacity of Shanghai exhibited an increasing BCI from 1993-1997, denoting the internal infilling nature of its urban expansion. After 1997, Shanghai's BCIs began to decline, showing that urban development in Shanghai has involved rapid external sprawl and suburbanization since 1997. BCIs of the Nanjing metropolitan circle show similar expansion tendencies as those of the core megacity of Shanghai. Its BCIs increased prior to 1997 and then decreased until 2012. The Hangzhou and Ningbo metropolitan circles underwent different processes from those of the megacity of Shanghai and of 
the Nanjing metropolitan circle. Over the 20-year period, the BCIs of the two metropolitan circles gradually decreased, showing that corresponding urban built-up areas underwent external sprawl and suburbanization over a long time period. The BCIs of the Hefei and Suxichang metropolitan circles exhibited "decreasing-increasing-decreasing" tendencies over the 20-year period, explaining significant variations in corresponding urban expansion spatial patterns occurring from 1993 to 2012. BCIs of the core megacity of Shanghai and of the five metropolitan circles underwent a pronounced decrease after 2007. Among the five metropolitan circles examined, BCIs of the Nanjing metropolitan circle were found to be greater than those of the other four, indicating that its built-up area is the densest and most efficient.

Table 2. Buffer compactness indexes (BCIs) of the core megacity of Shanghai and five metropolitan circles for 1993-2012.

\begin{tabular}{cccccc}
\hline \multirow{2}{*}{ The YRDUA } & \multicolumn{5}{c}{ Bcis of Five Years } \\
\cline { 2 - 6 } & $\mathbf{1 9 9 3}$ & $\mathbf{1 9 9 7}$ & $\mathbf{2 0 0 2}$ & $\mathbf{2 0 0 7}$ & $\mathbf{2 0 1 2}$ \\
\hline Megacity of Shanghai & 0.519 & 0.541 & 0.483 & 0.380 & 0.380 \\
Nanjing metropolitan circle & 0.291 & 0.297 & 0.237 & 0.236 & 0.224 \\
Hangzhou metropolitan circle & 0.307 & 0.231 & 0.207 & 0.17 & 0.167 \\
Hefei metropolitan circle & 0.316 & 0.236 & 0.239 & 0.211 & 0.162 \\
Suxichang metropolitan circle & 0.240 & 0.202 & 0.164 & 0.166 & 0.159 \\
Ningbo metropolitan circle & 0.216 & 0.212 & 0.164 & 0.164 & 0.161 \\
\hline
\end{tabular}

\subsection{Urban Expansion Evaluation Analysis}

Table 3 shows the elastic coefficients of urban expansion-population growth for 1993-2012 for the YRDUA, for the core megacity of Shanghai and for the five metropolitan circles. Elastic coefficients of the YRDUA varied greatly across the 20-year period and remained above the desired value of 1.12. This shows that the urban built-up area of the YRDUA expanded too fast from 1993-2012 and that urban expansion did not match urban non-agricultural population growth. For the periods examined, the elastic coefficient for 2002-2007 most closely approached reasonable values 1.25 times, showing considerable improvements in the intensive use of YRDUA urban built-up land.

The Nanjing metropolitan circle presented excessively low elastic coefficients of urban-expansionpopulation growth over the 20-year period, and most elastic coefficients remained lower than the desired value except from 1997-2002. Thus, urban expansion in the Nanjing metropolitan circle did not meet its rapid urban non-agricultural population growth. On the other hand, elastic coefficients of the Hangzhou and Ningbo metropolitan circles underwent an initial increase and subsequent decrease from 1993-2012. From 2008-2012, elastic coefficients of both metropolitan circles approached 1.12, revealing strong coordination between urban built-up area expansion and non-agricultural population growth. However, for much of the 20-year period, elastic coefficients of the two metropolitan circles were much larger than the desired value, reaching peak values of 3.3 and 4.1. The Hefei metropolitan circle presented an excessively high elastic coefficient over the 20-year period, with peak values reaching 5.3 times the desired value, denoting the excessive external expansion of its urban built-up area. The megacity of Shanghai and Suxichang metropolitan circle showed a decline in elastic coefficients of urban expansion and population growth over the 20-year period, denoting an improvement in coordination between corresponding urban built-up areas and urban non-agricultural population growth. The megacity of Shanghai still presented slightly excessive urban expansion patterns from 2007-2012, with an elastic coefficient exceeding the desired value of 1.12. In contrast, the elastic coefficient for the Suxichang metropolitan circle decreased to 0.8 , revealing inconsistencies between strained urban expansion patterns and population growth from 2007-2012. 
Table 3. Elastic coefficients of urban expansion-population growth for the YRDUA for 1993-2012.

\begin{tabular}{ccccc}
\hline & $\mathbf{1 9 9 3 - 1 9 9 7}$ & $\mathbf{1 9 9 8 - 2 0 0 2}$ & $\mathbf{2 0 0 3 - 2 0 0 7}$ & $\mathbf{2 0 0 8 - 2 0 1 2}$ \\
\hline The whole YRDUA & 2.18 & 2.66 & 1.40 & 1.83 \\
Megacity of Shanghai & 6.07 & 3.82 & 3.05 & 1.78 \\
Nanjing metropolitan circle & 0.73 & 3.30 & 0.62 & 1.05 \\
Hangzhou metropolitan circle & 2.64 & 3.65 & 1.95 & 1.35 \\
Hefei metropolitan circle & 4.63 & 2.69 & 1.74 & 5.93 \\
Suxichang metropolitan circle & 5.14 & 2.53 & 2.41 & 0.80 \\
Ningbo metropolitan circle & 1.59 & 3.89 & 4.56 & 1.45 \\
\hline
\end{tabular}

\section{Discussion}

In the last section, we comprehensively analyzed the urban expansion characteristics of the YRDUA based on three main variables: urban expansion rates, urban expansion spatial patterns and urban expansion evaluations. The AGAs of built-up areas were used to quantify the urban expansion of the YRDUA and its five metropolitan circles. The analysis results show that the YRDUA generally experienced an increasing expansion rate from 1993-2007 but that heterogeneous expansion occurred within its five metropolitan circles over the 20-year period. Before 2007, most of the metropolitan circles exhibited increasing expansion rates. The expansion rates of most of the metropolitan circles examined drastically declined from 2007-2012. Such patterns found in most the metropolitan circles and for the YRDUA as a whole are attributed to the global financial crisis of 2007-2009, which brought about the slowdown in economic growth and which negatively affected urban expansion in the YRDUA. The financial crisis of 2007-2009 had three main negative effects on the YRDUA. First, overall growth in foreign trade imports and exports slowed after 2007, and export trade in the YRDUA suffered serious impacts. Second, overall industrial growth in the YRDUA declined, and the profits of industrial enterprises dropped significantly. Finally, the land acquisition and development area of the YRDUA decreased, and the expansion rate of its urban built-up area declined. The more significant declines in urban expansion rates found for the Suxichang and Ningbo metropolitan circles are attributed to a stronger dependence on foreign trade. Reduced trade requirements from overseas countries led to conditions of urban economic depression in the two metropolitan circles and affected their urban expansion construction patterns accordingly.

On the other hand, sources of urban expansion in the five metropolitan circles from 1993-2012 were identified. Rapid population growth driven by rural-urban migration and rapid economic development constituted the main contributing factors to the urban expansion of the Nanjing metropolitan circle prior to 2002. Its slow urban expansion rate from 2002-2007 is attributed to rapid population growth, relatively low infrastructure construction rates, and the institution of limited plans and policies (e.g., land reforms, guided land development, and government economic and investment plans). Infrastructure construction (e.g., transportation, electricity, education, and health services) and fixed asset investments (e.g., commercial housing and recreation facilities) served as major driving forces behind its urban expansion after 2007. For the Hangzhou metropolitan circle, rapid population growth through urbanization and a rapid increase in Gross Domestic Product (GDP) contributed to its increasing urban expansion rate from 1993-2007, and its urban expansion after 2007 was mainly driven by updates to industrial structures, economic development, and policy support from the Zhejiang provincial government, although urban expansion rates declined. The urban expansion of the Hefei metropolitan circle has consistently been driven by continuous population growth and economic development, especially since 2007. Moreover, the financial crisis of 2007-2009 had a less significant impact on its economic development and urban expansion. Driving forces of urban expansion in the Ningbo metropolitan circle prior to 2007 include rapid population and GDP growth. The urban expansion rate decreased after 2007 and is mainly attributed to a slow economic transition and to slow population growth. Rapid population growth and increases in GDP increased the urban expansion 
rate of the Suxichang metropolitan circle from 1993 to 2007, and its urban expansion since 2007 has mainly been driven by rapid population growth and fixed asset investment from the local government.

The SDE and BCI were further examined to analyze spatial patterns of the YRDUA and of its five metropolitan circles. The SDE reveals spatial characteristics of the geospatial distribution of a point location set from its elements, i.e., the center, the major and minor axes, and the rotation angle. BCIs quantify levels of urban compactness from spatial external contours. Changes in SDE center locations show that the YRDUA experienced urban expansion from northeast to southwest from 1993-2012. Moreover, BCIs of the YRDUA generally increased from 1993-2007 and then decreased after 2007. This shows that the YRDUA first experienced internal infilling expansion from 1993-2007 and external sprawl and suburbanization after 2007. The Nanjing metropolitan circle underwent urban expansion in the northeastern direction and rapid external expansions of its built-up area after 1997. The Hangzhou metropolitan circle shifted south and west, and it underwent external sprawl and suburbanization over the 20-year period. The urban expansion of the Hefei metropolitan circle has mainly been oriented southward. Its expansion pattern diverged greatly across the 20-year period and shifted from patterns of internal infilling to patterns of external sprawl and suburbanization. The Suxichang metropolitan circle underwent similar expansion patterns as those of the Hefei metropolitan circle. The Ningbo metropolitan circle underwent urban expansion to the southeast, and an increase in its urban built-up area mainly resulted from external sprawl and suburbanization. Figure 8 further plots the rotation angle and oblateness of SDEs of the YRDUA for 1993 to 2012. Over the 20-year period, the rotation angle of SDEs of the YRDUA increased from $122.5^{\circ}$ to $144.2^{\circ}$. This shows that the whole YRDUA underwent a counter-clockwise rotation in urban expansion. Though not for the year 2007, the oblateness of YRDUA SDEs generally declined over the 20 -year period from 0.43 to 0.35 . This shows that urban expansion in the YRDUA has exhibited less predictable patterns than ever before and has begun to exhibit a diverging tendency to the northeast and southwest.

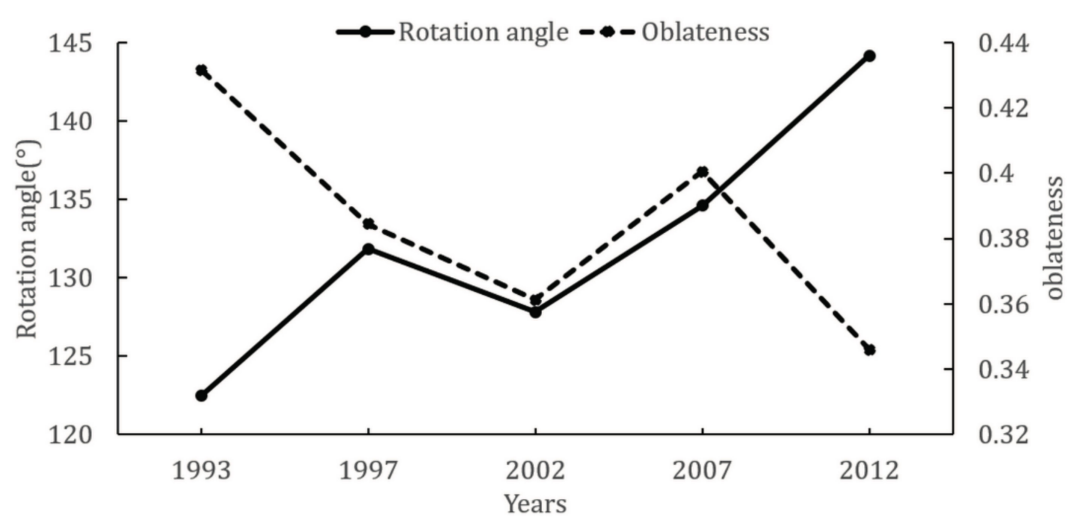

Figure 8. Plots of rotation angles and oblateness values for YRDUA SDEs for 1993-2012.

Finally, we used the elastic coefficient of urban expansion-population growth to evaluate patterns of urban expansion. The larger elastic coefficient found for the YRDUA for 1993-2012 reveals inconsistencies between rapid urban expansion rates and urban non-agricultural population growth. Fortunately, the elastic coefficient has exhibited a declining tendency. The Hefei metropolitan circle has experienced an excessively rapid urban expansion rate, bringing about a serious lag in its urban non-agricultural population growth. The urban expansion of the Hangzhou and Ningbo metropolitan circles has not coincided with urban non-agricultural population growth, though patterns have gradually improved since 2007. The megacity of Shanghai and the Suxichang metropolitan circle show a considerable decrease in elastic coefficients, and coordination between urban expansion and urban population growth continually improved over the 20-year period. Unlike most metropolitan circles, the Nanjing metropolitan circle has always presented a smaller elastic coefficient of urban 
expansion and population growth. This again verifies that external sprawl and suburbanization in the Nanjing metropolitan circle do not complement patterns of population growth.

This paper presents limitations that further studies must address. First, the urban extent applied in this paper is limited to the artificial surfaces of municipal districts of individual cities, and we do not consider artificial surfaces of county or suburban areas. As a result, we extracted fewer urban light pixels than other similar studies, although this did not affect the main conclusions of our study. Second, we did not use land cover information to carefully verify the spatial extents of extracted urban built-up areas from the corrected DMSP/OLS NTL data. In our future work, land cover mapping products (available at http:/ / www.globallandcover.com/GLC30Download/index.aspx) of the YRDUA will be used as an auxiliary dataset to further improve the spatial accuracy of urban built-up areas identified. Third, due to DMSP/OLS data limitations, urban expansion patterns occurring after 2012 were not investigated. New National Polar-orbiting Partnership Visible Infrared Imaging Radiometer Suite (NPP/VIIRS) (available at https:/ /ngdc.noaa.gov/eog/viirs/download_ dnb_composites.html) NTL data could be used to further explore urban expansion characteristics of the YRDUA from 2012. Finally, we only examined urban expansion general characteristics of the YRDUA based on four indices. In future work, more geographic indices, e.g., fractal dimensions of urban built-up areas [57] and the urban expansion intensity index [58], should be used to further explore urban expansion characteristics of the YRDUA. Moreover, landscape pattern indices for land cover data derived from Landsat imagery or high spatial resolution images and ecosystem service values can be used to explore changes in landscape patterns and ecosystem service values resulting from land use changes [59]. Finally, internal urban structure changes must be investigated from DMSP/OLS data to better understand changing economic activities. The topographical metaphor for light intensity values can be used to identify urban centers and subcenters, and the surface slope of light intensity can be used to determine urban land use intensity gradients [60].

\section{Conclusions}

In this paper, we investigated urban expansion characteristics of the YRDUA from DMSP/OLS NTL data for 1993-2012. Urban extents of the YRDUA for 1993, 1997, 2002, 2007, and 2012 were extracted from corrected DMSP/OLS NTL data. Four main indices were used to comprehensively analyze urban expansion characteristics of the YRDUA based on three main variables: urban expansion rates, urban expansion spatial patterns, and status evaluations. Compared to past works, this paper provides a more detailed account of urban expansion patterns occurring in the YRDUA and within its five metropolitan circles. The main conclusions of this paper are as follows:

(1) The YRDUA experienced increasing rates of urban expansion rates from 1993-2007, and urban expansion rates decreased after 2007 as a result of the global financial crisis of 2007-2009. For the metropolitan circles examined, urban expansion rates within the Suxichang and Ningbo metropolitan circles were seriously affected by the financial crisis after 2007. By contrast, the Hefei metropolitan circle maintained an increasing expansion rate over the 20-year period.

(2) Urban expansion of the YRDUA mainly occurred from the northeast to the southwest over the 20-year period. Urban expansion spatial patterns in the YRDUA involved internal infill from 1993-2007, and then external sprawl and suburbanization from 2007. In contrast to three other metropolitan circles, the Hefei and Suxichang metropolitan circles experienced more variations in urban expansion patterns over the 20-year period, shifting from internal infilling to external suburbanization.

(3) Urban expansion in the YRDUA was not consistent with its urban non-agricultural population growth, though this pattern was gradually alleviated overall. The megacity of Shanghai exhibited stronger coordination between urban expansion and urban non-agricultural population growth during the study period. By contrast, the Nanjing metropolitan circle experienced urban built-up land stress and thus could not meet needs for non-agricultural population growth over the 20-year period. 
Acknowledgments: This work was funded by the National Natural Science Foundation (41671342, U1609203), by the Chinese Postdoctoral Science Foundation (2015M570668, 2016T90732), by the Ningbo Natural Science Foundation (2017A610294), and by the K. C. Wong Magna Fund of Ningbo University. The authors would like to thank the editor and referees for their suggestions, which improved the paper.

Author Contributions: All coauthors made significant contributions to the paper. Huimin Lu and Meiliang Zhang determined the paper's focus on urban expansion in the YRDUA. Weiyue Li calibrated the DMSP/OLS NTL data and extracted urban extents of the YRDUA. Weiwei Sun provided expertise on remote sensing and helped revise the paper.

Conflicts of Interest: The authors declare no conflict of interest.

\section{References}

1. Montgomery, M.R. The urban transformation of the developing world. Science 2008, 319, 761-764. [CrossRef] [PubMed]

2. Ma, T.; Zhou, Y.; Zhou, C.; Haynie, S.; Pei, T.; Xu, T. Night-time light derived estimation of spatio-temporal characteristics of urbanization dynamics using DMSP/OLS satellite data. Remote Sens. Environ. 2015, 158, 453-464. [CrossRef]

3. Weng, Q. A remote sensing? GIS evaluation of urban expansion and its impact on surface temperature in the Zhujiang Delta, China. Int. J. Remote Sens. 2001, 22, 1999-2014.

4. $\mathrm{Xu}, \mathrm{X}$.; Min, X. Quantifying spatiotemporal patterns of urban expansion in China using remote sensing data. Cities 2013, 35, 104-113. [CrossRef]

5. Bai, X.; Shi, P.; Liu, Y. Society: Realizing China's urban dream. Nature 2014, 509, 158-160. [CrossRef] [PubMed]

6. Li, X.; Zhou, W.; Ouyang, Z. Forty years of urban expansion in Beijing: What is the relative importance of physical, socioeconomic, and neighborhood factors? Appl. Geogr. 2013, 38, 1-10. [CrossRef]

7. He, C.; Gao, B.; Huang, Q.; Ma, Q.; Dou, Y. Environmental degradation in the urban areas of China: Evidence from multi-source remote sensing data. Remote Sens. Environ. 2017, 193, 65-75. [CrossRef]

8. Byomkesh, T.; Nakagoshi, N.; Dewan, A.M. Urbanization and green space dynamics in Greater Dhaka, Bangladesh. Landsc. Ecol. Eng. 2012, 8, 45-58. [CrossRef]

9. Zhang, P.; Liu, S.; Du, J. A map spectrum-based spatiotemporal clustering method for GDP variation pattern analysis using nighttime light images of the Wuhan urban agglomeration. ISPRS Int. J. Geo-Inf. 2017, 6, 160. [CrossRef]

10. Faisal, K.; Shaker, A.; Habbani, S. Modeling the relationship between the gross domestic product and built-up area using remote sensing and GIS data: A case study of seven major cities in Canada. ISPRS Int. J. Geo-Inf. 2016, 5, 23. [CrossRef]

11. Ju, Y.; Dronova, I.; Ma, Q.; Zhang, X. Analysis of urbanization dynamics in mainland China using pixel-based night-time light trajectories from 1992 to 2013. Int. J. Remote Sens. 2017, 38, 6047-6072. [CrossRef]

12. Liu, Z.; He, C.; Zhang, Q.; Huang, Q.; Yang, Y. Extracting the dynamics of urban expansion in China using DMSP-OLS nighttime light data from 1992 to 2008. Landsc. Urban Plan. 2012, 106, 62-72. [CrossRef]

13. Thapa, R.B.; Murayama, Y. Drivers of urban growth in the Kathmandu Valley, Nepal: Examining the efficacy of the analytic hierarchy process. Appl. Geogr. 2010, 30, 70-83. [CrossRef]

14. Moghadam, H.S.; Helbich, M. Spatiotemporal urbanization processes in the megacity of Mumbai, India: A Markov chains-cellular automata urban growth model. Appl. Geogr. 2013, 40, 140-149. [CrossRef]

15. Dewan, A.M.; Yamaguchi, Y. Land use and land cover change in greater Dhaka, Bangladesh: Using remote sensing to promote sustainable urbanization. Appl. Geogr. 2009, 29, 390-401. [CrossRef]

16. Zhu, Z.; Woodcock, C.E. Object-based cloud and cloud shadow detection in Landsat imagery. Remote Sens. Environ. 2012, 118, 83-94. [CrossRef]

17. Sun, W.; Du, B.; Xiong, S. Quantifying sub-pixel surface water coverage in urban environments using low-albedo fraction from Landsat imagery. Remote Sens. 2017, 9, 428. [CrossRef]

18. Elvidge, C.D.; Baugh, K.E.; Dietz, J.B.; Bland, T.; Sutton, P.C.; Kroehl, H.W. Radiance calibration of DMSP-OLS low-light imaging data of human settlements. Remote Sens. Environ. 1999, 68, 77-88. [CrossRef]

19. Elvidge, C.D.; Imhoff, M.L.; Baugh, K.E.; Hobson, V.R.; Nelson, I.; Safran, J.; Dietz, J.B.; Tuttle, B.T. Night-time lights of the world: 1994-1995. ISPRS J. Photogramm. Remote Sens. 2001, 56, 81-99. [CrossRef]

20. Elvidge, C.D.; Ziskin, D.; Baugh, K.E.; Tuttle, B.T.; Ghosh, T.; Pack, D.W.; Erwin, E.H.; Zhizhin, M. A fifteen year record of global natural gas flaring derived from satellite data. Energies 2009, 2, 595-622. [CrossRef] 
21. Li, X.; Zhou, Y. Urban mapping using DMSP/OLS stable night-time light: A review. Int. J. Remote Sens. 2017, 38, 6030-6046. [CrossRef]

22. Guo, W.; Lu, D.; Kuang, W. Improving fractional impervious surface mapping performance through combination of DMSP-OLS and MODIS NDVI data. Remote Sens. 2017, 9, 375. [CrossRef]

23. Liu, X.; Hu, G.; Ai, B.; Li, X.; Shi, Q. A normalized urban areas composite index (NUACI) based on combination of DMSP-OLS and MODIS for mapping impervious surface area. Remote Sens. 2015, 7, 17168-17189. [CrossRef]

24. Li, C.; Li, G.; Zhu, Y.; Ge, Y.; Wu, Y. A likelihood-based spatial statistical transformation model (LBSSTM) of regional economic development using DMSP/OLS time series and nighttime light imagery. Spat. Stat. 2017, 21, 421-439. [CrossRef]

25. Dai, Z.; Hu, Y.; Zhao, G. The suitability of different nighttime light data for GDP estimation at different spatial scales and regional levels. Sustainability 2017, 9, 305. [CrossRef]

26. Cao, X.; Wang, J.; Chen, J.; Shi, F. Spatialization of electricity consumption of China using saturation-corrected DMSP-OLS data. Int. J. Appl. Earth Obs. Geoinf. 2014, 28, 193-200. [CrossRef]

27. Xie, Y.; Weng, Q. Detecting urban-scale dynamics of electricity consumption at Chinese cities using time-series DMSP-OLS (Defense Meteorological Satellite Program-Operational Linescan System) nighttime light imageries. Energy 2016, 100, 177-189. [CrossRef]

28. Jiang, W.; He, G.; Long, T.; Wang, C.; Ni, Y.; Ma, R. Assessing light pollution in China based on nighttime light imagery. Remote Sens. 2017, 9, 135. [CrossRef]

29. Tripathi, B.R.; Tiwari, V.; Pandey, V.; Elvidge, C.; Rawat, J.-S.; Sharma, M.; Pravasi, R.; Kumar, P. Estimation of urban population dynamics using DMSP-OLS night-time lights time series sensors data. IEEE Sens. J. 2017, 17, 1013-1020. [CrossRef]

30. Huang, Q.; Yang, Y.; Li, Y.; Gao, B. A simulation study on the urban population of China based on nighttime light data acquired from DMSP/OLS. Sustainability 2016, 8, 521. [CrossRef]

31. Shi, K.; Huang, C.; Yu, B.; Yin, B.; Huang, Y.; Wu, J. Evaluation of NPP-VIIRS night-time light composite data for extracting built-up urban areas. Remote Sens. Lett. 2014, 5, 358-366. [CrossRef]

32. Xie, Y.; Weng, Q. Updating urban extents with nighttime light imagery by using an object-based thresholding method. Remote Sens. Environ. 2016, 187, 1-13. [CrossRef]

33. He, C.; Shi, P.; Li, J.; Chen, J.; Pan, Y.; Li, J.; Zhuo, L.; Ichinose, T. Restoring urbanization process in China in the 1990s by using non-radiance-calibrated DMSP/OLS nighttime light imagery and statistical data. Chin. Sci. Bull. 2006, 51, 1614-1620. [CrossRef]

34. Ma, T.; Zhou, C.; Pei, T.; Haynie, S.; Fan, J. Quantitative estimation of urbanization dynamics using time series of DMSP/OLS nighttime light data: A comparative case study from China's cities. Remote Sens. Environ. 2012, 124, 99-107. [CrossRef]

35. Zhang, Q.; Seto, K.C. Mapping urbanization dynamics at regional and global scales using multi-temporal DMSP/OLS nighttime light data. Remote Sens. Environ. 2011, 115, 2320-2329. [CrossRef]

36. Liu, Y.; Wang, Y.; Peng, J.; Du, Y.; Liu, X.; Li, S.; Zhang, D. Correlations between urbanization and vegetation degradation across the world's metropolises using DMSP/OLS nighttime light data. Remote Sens. 2015, 7, 2067-2088. [CrossRef]

37. Cai, D.; Fraedrich, K.; Guan, Y.; Guo, S.; Zhang, C. Urbanization and the thermal environment of Chinese and US-American cities. Sci. Total Environ. 2017, 589, 200-211. [CrossRef] [PubMed]

38. Xie, Y.; Weng, Q. Spatiotemporally enhancing time-series DMSP/OLS nighttime light imagery for assessing large-scale urban dynamics. ISPRS J. Photogramm. Remote Sens. 2017, 128, 1-15. [CrossRef]

39. Gao, B.; Huang, Q.; He, C.; Ma, Q. Dynamics of urbanization levels in China from 1992 to 2012 : Perspective from DMSP/OLS nighttime light data. Remote Sens. 2015, 7, 1721-1735. [CrossRef]

40. Tan, M. Urban growth and rural transition in China based on DMSP/OLS nighttime light data. Sustainability 2015, 7, 8768-8781. [CrossRef]

41. Yi, K.; Tani, H.; Li, Q.; Zhang, J.; Guo, M.; Bao, Y.; Wang, X.; Li, J. Mapping and evaluating the urbanization process in northeast China using DMSP/OLS nighttime light data. Sensors 2014, 14, 3207-3226. [CrossRef] [PubMed]

42. Li, Q.; Lu, L.; Weng, Q.; Xie, Y.; Guo, H. Monitoring urban dynamics in the southeast USA using time-series DMSP/OLS nightlight imagery. Remote Sens. 2016, 8, 578. [CrossRef] 
43. Gao, B.; Huang, Q.; He, C.; Dou, Y. Similarities and differences of city-size distributions in three main urban agglomerations of China from 1992 to 2015: A comparative study based on nighttime light data. J. Geogr. Sci. 2017, 27, 533-545. [CrossRef]

44. Huang, Q.; He, C.; Gao, B.; Yang, Y.; Liu, Z.; Zhao, Y.; Dou, Y. Detecting the 20 year city-size dynamics in China with a rank clock approach and DMSP/OLS nighttime data. Landsc. Urban Plan. 2015, 137, 138-148. [CrossRef]

45. Zou, Y.; Peng, H.; Liu, G.; Yang, K.; Xie, Y.; Weng, Q. Monitoring urban clusters expansion in the middle reaches of the Yangtze River, China, using time-series nighttime light images. Remote Sens. 2017, 9, 1007. [CrossRef]

46. Zhou, J.; Lu, M. Spatial characteristics of urban agglomeration in the middle reaches of Yangtze River using MODIS data and DMSP/OLS nighttime light data. Mod. Urban Res. 2017, 4, 14-20.

47. Wang, Z.; Yang, S.; Wang, S.; Shen, Y. Monitoring evolving urban cluster systems using DMSP/OLS nighttime light data: A case study of the Yangtze River Delta region, China. J. Appl. Remote Sens. 2017, 11, 046029. [CrossRef]

48. Wang, R.; Wan, B.; Guo, Q.; Hu, M.; Zhou, S. Mapping regional urban extent using NPP-VIIRS DNB and MODIS NDVI data. Remote Sens. 2017, 9, 862. [CrossRef]

49. Shao, Z.; Liu, C. The integrated use of DMSP-OLS nighttime light and MODIS data for monitoring large-scale impervious surface dynamics: A case study in the Yangtze River Delta. Remote Sens. 2014, 6, 9359-9378. [CrossRef]

50. Elvidge, C.D.; Baugh, K.E.; Kihn, E.A.; Kroehl, H.W.; Davis, E.R. Mapping city lights with nighttime data from the DMSP operational Linescan system. Photogramm. Eng. Remote Sens. 1997, 63, 727-734.

51. Imhoff, M.L.; Lawrence, W.T.; Stutzer, D.C.; Elvidge, C.D. A technique for using composite DMSP/OLS “city lights" satellite data to map urban area. Remote Sens. Environ. 1997, 61, 361-370. [CrossRef]

52. Sutton, P. Modeling population density with night-time satellite imagery and GIS. Comput. Environ. Urban Syst. 1997, 21, 227-244. [CrossRef]

53. Lefever, D.W. Measuring geographic concentration by means of the standard deviational ellipse. Am. J. Sociol. 1926, 32, 88-94. [CrossRef]

54. Chen, J.; Zhuo, L.; Shi, P.-J.; Toshiaki, I. The study on urbanization process in China based on DMSP/OLS data: Development of a light index for urbanization level estimation. J. Remote Sens. 2003, 7, 168-175.

55. Li, X.; Yeh, A.G.-O. Analyzing spatial restructuring of land use patterns in a fast growing region using remote sensing and GIS. Landsc. Urban Plan. 2004, 69, 335-354. [CrossRef]

56. Zhao, M.; Cai, H.; Qiao, Z.; Xu, X. Influence of urban expansion on the urban heat island effect in Shanghai. Int. J. Geogr. Inf. Sci. 2016, 30, 2421-2441. [CrossRef]

57. Zhang, Z.; Xiao, R.; Yu, W.; Liu, Y.; Lin, M.; Wang, M. Characterizing factors associated with built-up land expansion in urban and non-urban areas from a morphological perspective. Sustainability 2017, 9, 1411. [CrossRef]

58. Haijun, W.; Chang, X.; Anqi, Z. Space syntax expand intensity index and its applications toquantitative analysis of urban expansion. Acta Geogr. Sin. 2016, 71, 1302-1314.

59. Su, S.; Xiao, R.; Jiang, Z.; Zhang, Y. Characterizing landscape pattern and ecosystem service value changes for urbanization impacts at an eco-regional scale. Appl. Geogr. 2012, 34, 295-305. [CrossRef]

60. Chen, Z.; Yu, B.; Song, W.; Liu, H.; Wu, Q.; Shi, K.; Wu, J. A new approach for detecting urban centers and their spatial structure with nighttime light remote sensing. IEEE Trans. Geosci. Remote Sens. 2017, 55, 6305-6319. [CrossRef]

(C) 2018 by the authors. Licensee MDPI, Basel, Switzerland. This article is an open access article distributed under the terms and conditions of the Creative Commons Attribution (CC BY) license (http://creativecommons.org/licenses/by/4.0/). 